This is the peer reviewed version of the following article: Martínez-Virto, L, Sánchez-Salmerón, V. Regional responses to social changes in Spain. Trends and policy challenges for social cohesion. Reg Sci Policy Pract. 2020; 1- 16. which has been published in final form at https://doi.org/10.1111/rsp3.12330. This article may be used for non-commercial purposes in accordance with Wiley Terms and Conditions for Use of Self-Archived Versions.

\title{
Regional responses to social changes in Spain. Trends and policy challenges for social cohesion ${ }^{1}$
}

\author{
Lucía Martínez-Virto \\ Víctor Sánchez-Salmerón \\ Sociology and Social Work Department \\ Public University of Navarre, Spain \\ Correspondence: lucia.martinez@unavarra.es
}

Funding information: Ministerio de Ciencia e Innovación,

Grant/Award Number: CSO2014-51901-P

\begin{abstract}
Inclusion policies in Spain are regional and local instruments aimed at reducing inequalities and generating social cohesion. The 2008 economic crisis had a strong social impact throughout the country, increasing exclusion situations for the most vulnerable groups. Throughout this text, the evolution of social inclusion regulatory measures of five territories in Spain in the last decade is presented. This review identifies strong interterritorial differences in the treatment of social problems. The interest of this work lies in two significant novelties. In terms of methodology, this work analyses the main normative instruments on inclusion. Furthermore, the analysis provides an integral view allowing the identification of development models, current trends and responses to the crisis. The conclusions provide five contributions that may be of interest for the consolidation and development of these policies in Spain, but also applicable in an international context.
\end{abstract}

\section{Keywords}

Social cohesion, employment, crisis, minimum income, social services

\footnotetext{
${ }^{1}$ This work was supported by the Spanish Ministry of Economy and Competitiveness under (CSO201451901-P). The project was conducted by Public University of Navarre with the participation of four universities: Pablo de Olavide University, University of Murcia, University of Valladolid and University of La Rioja.
} 


\section{Introduction}

The fight against poverty and social exclusion has been a target for European countries since the late 1980s (Atkinson \& Davoudi, 2000; Atkinson, 2002; Silver, 2012). However, it was during the first decade of this century that the social agenda received a solid boost. With the launch of the Lisbon Strategy (2000), the social inclusion agenda emerged strongly, especially linked to other wide-ranging debates such as those on social integration, equal opportunities or social cohesion. Currently, the mobilization has reached global repercussion through the 2030 Agenda, approved by the member states of the United Nations in 2015. The so-called Sustainable Development Goals reinforced the commitment of many European nations with the promotion of a more inclusive economic growth and higher welfare levels (Sachs, et al, 2019). Certainly, these and other similar initiatives contribute to defining and scheduling specific objectives to build more inclusive societies. However, the consensus is less evident when it comes to specifying policies and measures since aspects such as the political dimension, institutional inactivity, or the social pressure capacity influence them. Similarly, the social inclusion dynamics depend on local and regional factors in which they were developed, responding to the particular needs of the territories that continue without clear mechanisms for the coordination and transfer of initiatives (Silver, 2015).

The response to social exclusion has not been homogeneous, producing a variety of inclusive approaches and mechanisms amidst territories. Likewise, within the European Union, several inclusive discourses and projects also emerged. The general trend has evolved towards considering income guarantee programs, activation and labour integration measures, and regional social services as the main devices of inclusive actions (Frazer \& Marlier, 2014; Pérez Eransus, 2016; Rodríguez Cabrero \& Marbán Gallego, 2011). However, its evolution and development have remained very uneven, even despite increasing efforts to establish common goals and coordination methods.

A second element that introduces complexity when adopting a general overview is the diversity of levels and areas involved in the management. In recent decades, important governance reforms took place in Europe, seeking to provide greater decision-making capacity to social agents (Ferrera, 2005). Nevertheless, this bold decision has resulted in great regional discrepancies. (López-Santana \& Moyer, 2012). As a result of the so-called pluralism of well-being (Johnson, 1990), the parties involved in the financing, design and management of inclusive measures have been increasing, complicating not only the horizontal coordination horizontal but also the mapping of the actions put in place (PérezEransus, 2016).

It should also be noted that the analysis of inclusion policies cannot be detached from the evolution of social needs. The recent impact of the economic crisis and the austerity measures adopted had devastating effects on the social protection of the most vulnerable (Taylor Gooby, 2017). The intensification of needs reduced the levels of benefit coverage and inclusion resources. Moreover, the traditional debates around the deserving of 
benefits, the fear of generating dependency or the increasing demand might weaken the sustainability of those protection systems (Aguilar Hendrickson et al., 1995).

For all these reasons, the analysis and comparative study of inclusion policies have been particularly complex, making it difficult to obtain an overall perspective on inclusive agendas. These struggles in comparative measurement and analysis were found in the academic literature itself. At the international level, comparative analyses have been able to address the role of different social actors involved in the management of welfare measures (Abrahamson, 1995), collecting some local good practices too (Reuter, 2012; ESN 2016; EUNL, 2016 ). Likewise, interest has been placed on the comparative evolution at the regional and state level of the main indicators in the area of social exclusion (Atkinson \& Mariler, 2010; Förster, et al, 2003; EC, 2015). As well as in the comparative analysis of the impact and evolution in poverty reduction, especially those of income guarantee (OECD, 2017; Atkinson et al. 2010; Dalli, 2019; Van Lancker, 2016).

This has also been a general trend in Spain. In recent decades, significant efforts were made measuring social exclusion and its evolution from a multidimensional perspective (mainly through FOESSA reports, prepared periodically). Partial comparisons have also been carried out, both taking into account the models and regulations of social services (SIIS et al., 2017), and the regional minimum income programs (Ayala et al., 2018). Both studies showed how the protection scope, resource requirements and programs determined the inclusive capacity of the territories.

Both at the state and international levels, little attention has been paid to the study and comparative analysis of the regulations related to inclusion measures, despite the fact that its enactment is key to guide the inclusive schemas. In general, these agreements helped to articulate the responses and measures at the local and regional level. Joint studies of political and regulatory actions fighting poverty and social exclusion continue to be scarce, being limited to one specific instrument.

This article delves into precisely these study lines, based on the premise that a regulatory analysis allows us to understand the roots on which inclusion policies are designed and articulated, despite the aforementioned difficulties present in the most territories and regions. In the same way, it provides a wide perspective to identifying development models, responses to the crisis and current trends. The normative analysis is complemented by the assessment of key informants (technical and political managers), inclusion support beneficiaries (employment and social services) and minimum regional incomes. While the former allows us to examine the exchange of the norm into the practice, the latter identifies duplications and gaps in care.

As it is intended to demonstrate, this type of analysis is effective and accessible to approximate general trends in the inclusion field. This also allows taking into account the adjustments recently made at a time of great social transformations and adopting a 
comprehensive and integral approach that incorporates the main mechanisms for tackling poverty and exclusion (social services, income guarantee and job access).

This analysis was carried out in five autonomous communities (regions) of Spain, where the process of political and welfare administrative decentralization has created a very heterogeneous care chart (Gallego et al., 2003; Martínez-Virto and Sánchez-Salmeron, 2019), together with an intense recession impact (Laparra and Pérez, 2012; FOESSA 2014, FOESSA, 2018). A decade after the crisis, institutional measures continue to be assessed. New revisions have been developed showing the technical and political concerns regarding the ineffective response of regional protection systems to new social exclusion scenarios.

The article is organized as follows. The first part presents how social needs and inclusion regulations have evolved in Spain in recent decades. Subsequently, the analysis method is presented and applied to evaluate in-depth how the response progressed in the five selected regions. Finally, thanks to the comprehensive and dynamic analysis, the key factors and recommendations to consolidate inclusion policies and increase the inclusive potential in the territories will be identified, together with those sharing similar problems.

\section{Evolution of social needs and inclusion regulations in Spain}

In Spain, the main regional regulations related to inclusion were created in different periods, even considering the existence of various generations of social service laws (Vilá, 2010). The first one enclosed the second half of the eighties and the first half of the nineties (first-generation laws), and a more recent stage began in the second half from the 2000s (second generation). This is also the case of the Autonomous Minimum Income regulations (AMI onwards). Although there is a greater regulatory activity in the second stage, the development of the main regulatory milestones follows the same pattern, so it is also possible to speak of the existence of two different legislative periods (1990-2001 and 2007-2015).

The development of social rights within the country - and of inclusion policies by extension - was highly conditioned by the ideological debates around the restructuring of the welfare state and the socio-economic momentum (Rodríguez Cabrero, 2004). Ultimately, this would have caused, on the one hand, the decrease in the protection intensity and, on the other, the rigid response shown to emerging social needs.

In the particular case of the regulations related to social services, the rapid ascent of the unemployed population that followed the first regulatory stage (see GRAPHIC I) soon diminished their support reach. Designed especially to deal with classic situations of social marginality, the autonomous systems showed response limitations to many of the social transformations that occurred during the following decade. The second legislative stage was deployed fundamentally during the crisis period of 2007-2014, which limited many of the benefits and services- after a long period of regulatory drought - trying to address new profiles and exclusion situations. Today, nearly 4.1 million people are in a severe exclusion situation, an amount that has increased by $30 \%$ (1.2 million people) since 
2007 due to the maintenance of high unemployment and precariousness rates, but also due to persistent households in need (FOESSA, 2018; Martínez Virto, 2014).

At the same time, active employment competences were transferred to the autonomous communities (in a long process that extended from 1984 to 2010). Regional administrations have been in charge of establishing job guidance and training services based on their own needs (unemployment levels) and available employment opportunities. Although this has generated heterogeneous proposals, traditional access to inclusion programs and minimum benefits were strongly conditioned by the participation of people in situations of exclusion and activation measures. Nevertheless, employment policies targeted those sectors already employed or with work experience, neglecting those furthest from employment, limiting the capacity to attend to the growing volume of the unemployed population (Pérez Eransus et al. , 2019).

The first AMI regulations were enacted in the context of decreasing unemployment rates (see FIGURE II). Still in the 1990s, employment in most households - especially male employment - was stable and well paid. There was also a progressive post-crisis recovery in employment levels. But even in this favourable scenario, the latest economic safety net could not be adapted to the growing volume of the population excluded from the labour market (Moreno Fernández, 2001; Cortinas, 2017). The precarization of employment increased the number of vulnerable citizens during the following decades and strongly pressured regional AMI programs. This became even more obvious during the last 2008 crisis (second legislative period).

This pressure was also visible in the care field. The progressive incorporation of women into the labour market - and the transformation of family models - led to a notable increase in the need and demand for policies addressing dependency and family reconciliation. Spain is far from the European average in this arena and the System for Autonomy and Dependency Care (SAAD) was not consolidated yet. Born in 2006, it has proved incapable of attending all citizens demanding this right. The amount and intensity of the benefits have also been shown to be insufficient, appealing to the efforts - not only economic - by the families and households to subsist (AEDGSSSS, 2019).

GRAPH I. Evolution of regional legislation on social services and the unemployment rate (1980-2019). 


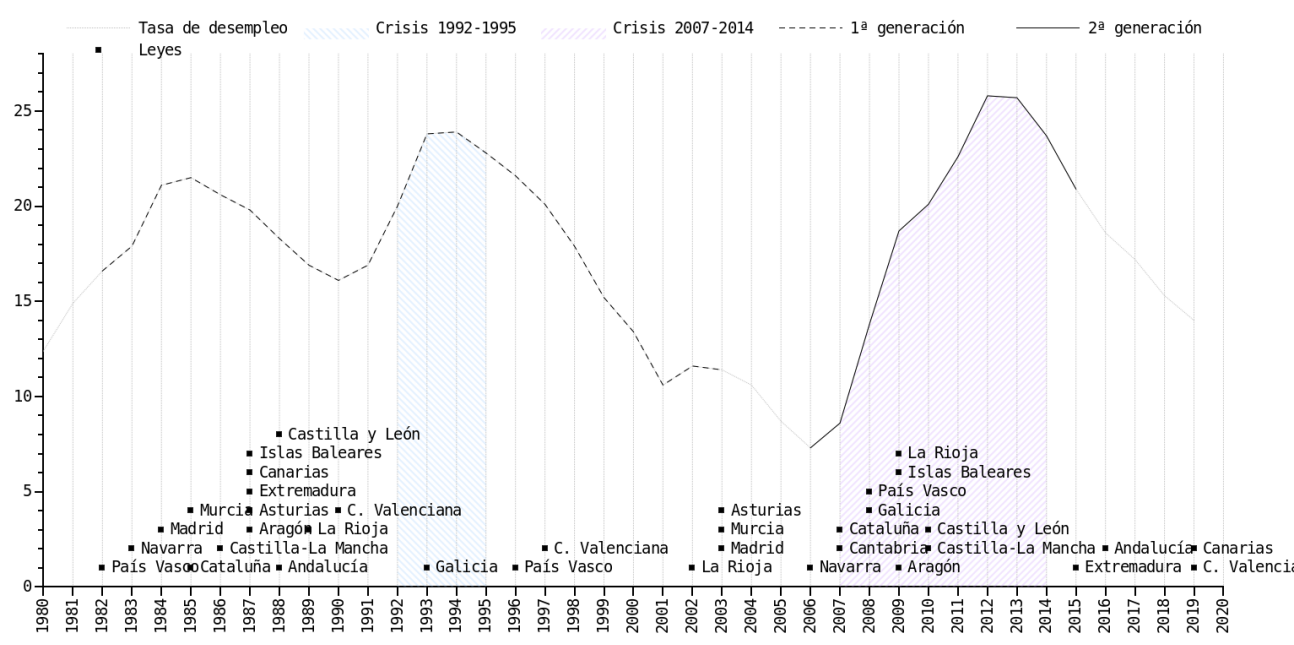

Source: Prepared by authors based on data from the National Institute of Statistics and the legislation review

GRAPH II. EVOLUTION OF REGIONAL LEGISLATION ON MINIMUM REGIONAL INCOMES AND UNEMPLOYMENT RATE (19892019).

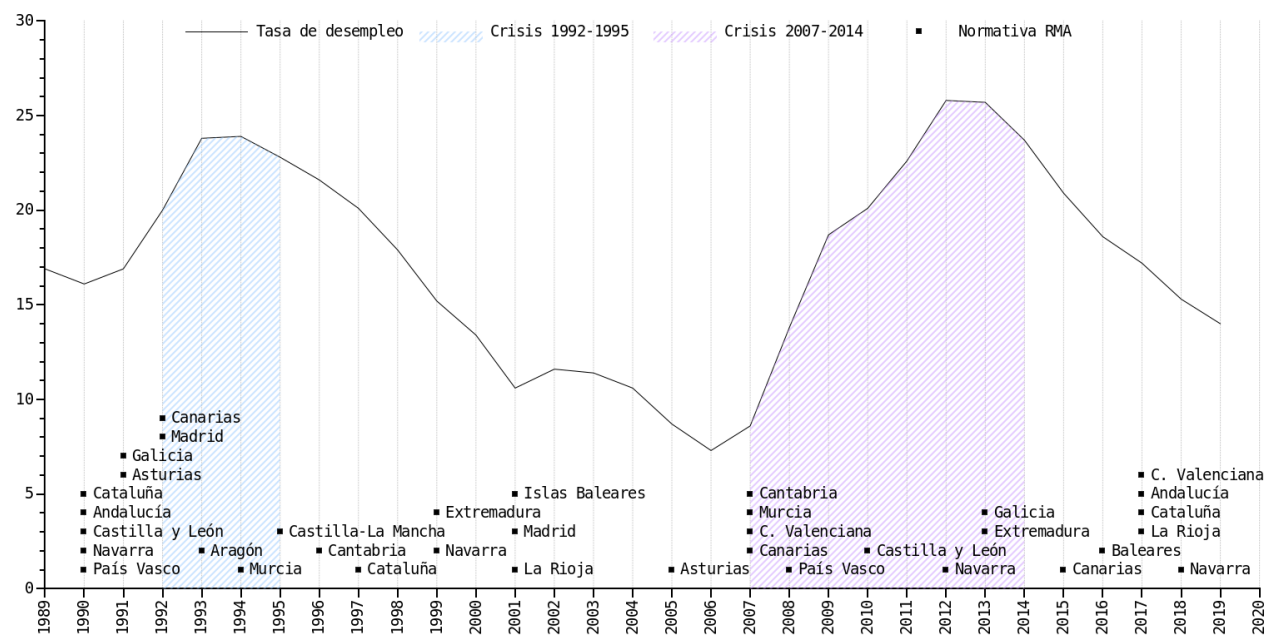

Source: Prepared by authors based on data from the National Institute of Statistics, and annual reports on Minimum income benefits (Ministry of Health, Consumption and Social Welfare )

The convergence of all these issues hindered the circumstances that regional inclusion policies had to face. Consequently, the level and intensity of the difficulties have also been different among territories. This is evident when examining some of the main international indicators applied, such as the rate of poverty-risk. Some areas of the country triple the values, with the highest being concentrated in the southern and central regions of the peninsula, and the lowest in the north and northwest.

However, this should not obscure the fact that most regions still face significant socioeconomic difficulties, as shown by some of the indicators linked to inclusion policies (See TABLE I). In 2018, all Spanish regions' unemployment rates were still 
above the European Union average (according to EUROSTAT data, the EU-28 unemployment rate is $6.8 \%$ ). In most regions, at least $20 \%$ of the population experiences multidimensional exclusion difficulties (problems in two or more areas: employment, consumption, education, health). Additionally, in those with lower unemployment and risk of poverty rates, the AMI coverage rates have been below the real volume of the vulnerable population.

TABLE I. Evolution of the risk of poverty rate (after social transfers), unemployment, exclusion and RMA coverage, by Autonomous Community (2018).

TABLE I. EVOLUTION OF THE RISK OF POVERTY RATE (AFTER SOCIAL TRANSFERS), UNEMPLOYMENT, EXCLUSION AND AMI COVERAGE, BY AUTONOMOUS COMMUNITY (2018).

\begin{tabular}{|c|c|c|c|c|}
\hline & Unemployment rate & Risk of povery rate* & $\begin{array}{c}\text { Multidimensional } \\
\text { exclusion** }(\%)\end{array}$ & AMI coverage*** \\
\hline Basque Country & 10,0 & 8,6 & 22,2 & 5,5 \\
\hline Navarre $^{* * * *}$ & 10,0 & 8,9 & 23,5 & 5,8 \\
\hline Catalunya & 11,5 & 13,6 & 26,1 & 1,3 \\
\hline Asturias & 13,6 & 14,0 & 19,1 & s.d \\
\hline Aragón & 10,6 & 14,2 & 19,3 & 1,8 \\
\hline Balear islands & 11,5 & 15,4 & 33,4 & 2,2 \\
\hline Castilla and León & 12,1 & 16,1 & 18,1 & 1,4 \\
\hline$\overline{\text { Madrid }}$ & 12,2 & 16,1 & 24,1 & 1,6 \\
\hline Rioja, La & 10,4 & 16,6 & 14,7 & s.d \\
\hline Galicia & 13,3 & 18,8 & 23,6 & 1,1 \\
\hline Cantabria & 10,7 & 19,9 & 18,6 & 1,9 \\
\hline Melilla & 25,8 & 21,4 & s.d. & s.d. \\
\hline C. Valencia & 15,6 & 26,0 & 27,0 & 0,7 \\
\hline Murcia & 16,8 & 28,6 & 26,0 & 1,0 \\
\hline Castilla- La Mancha & 18,2 & 29,9 & 22,4 & 0,4 \\
\hline Andalusia & 23,0 & 32,0 & 20,7 & 0,5 \\
\hline Canary Islands & 20,1 & 32,1 & 34,6 & 1,0 \\
\hline Extremadura & 23,6 & 37,6 & 24,7 & 2,0 \\
\hline$\overline{\text { Ceuta }}$ & 29,0 & 38,3 & s.d & 1,1 \\
\hline$\overline{\text { Total }}$ & 15,3 & 21,5 & 24,0 & 1,4 \\
\hline Difference max-min & 19,0 & 29,7 & 19,9 & 5,4 \\
\hline
\end{tabular}


* The poverty rates have been defined from national thresholds. The difference in the cost of living between regions makes it pertinent to use regional thresholds for a better approximation, however, they were not available for all the territories.

** Population that accumulates difficulties in two or more dimensions of social exclusion. According to the exclusión measurement proposal of the FOESSA indicator, there are a total of six dimensions (economic, employment, consumption, politics, education, housing and health).

$* * *$ Coverage of beneficiaries over the total population.

**** On bold: The five analyzed territories.

Source: Prepared by authors based on data from the National Institute of Statistics and EINSFOESSA

The demand pressure and the intensity of the difficulties have continued to be very high, therefore the hypothesis is based on assuming that this may have had a negative impact on the development of inclusion policies in the country. Even the mismatch between the intensity and volume of social needs and the responses would have occurred in those regions facing less serious situations.

The comparative analysis examines how Spanish regions have responded so differently to the worsening and transformation of needs, especially after the impact of the 2008 great recession. The study goes beyond describing common trends on inclusion policy evolution in the country but also identifies some key advances to consolidate the development of inclusion policies in an increasingly complex and changing scenario. The situation, that most countries in Europe and outside still face.

\section{Methodological aspects of the research}

As previously indicated, in addition to a comparative normative study, inclusion policies require understanding other social and political factors that explain their nature. For this reason, the comparative research takes five Spanish territories as case studies (Andalusia, Castilla y León, La Rioja, Murcia and Navarre). The selection criterion of the cases responds to a search of heterogeneity within the territories, comparing two large communities (Andalusia and Castilla León, eight and nine provinces respectively); and three of the smallest (Navarre, La Rioja and Murcia, one province each) (Manzaneda, et al. 2019; Jaráiz and González, 2019; Prieto, et. al, 2019). The selection also follows socioeconomic criteria. On the one hand, two communities, Andalusia and Murcia, stand out due to high unemployment, poverty and exclusion rates; two regions in which the impact of these indicators is intermediate (Castilla y León and La Rioja); and, finally, an autonomous community in which the incidence of the first two rates is one of the lowest in the country, Navarre (see Autonomous Communities marked in bold in Table I).

To identify the regulatory responses to the crisis, a qualitative study structured in three phases has been developed. First, a documentary analysis of primary normative sources related to inclusion has been carried out. Among them, inclusion and employment plans and strategies, minimum regional income regulations and laws and portfolios of social services promulgated in each territory. In the second phase, interviews and discussion groups were held with key informants in each of the participating territories. Interviews provided vital information on the practical application of inclusion resources and devices. 
Lastly, the study gathered life stories of support beneficiaries in order to approximate the analysis to the needs of the target population.

In total, the available empirical material on which these results are based is 28 in-depth semi-structured interviews ( 8 policy makers, 8 technical managers, 8 social workers, 4 third sector professionals), 13 discussion groups (4 social service professionals, 4 employment professionals and 4 of the third sector) and 18 life histories (9 men and 9 women of which 3 are of Romani ethnicity and 3 of foreign origin). All the empirical material has been recorded and partially transcribed, and the analysis is based on the next categories:

a) Definition of social inclusion, delimitation of the beneficiary population and the definition of intervention models based on policy texts and professional judgments;

b) How activation/inclusion actions are linked in each territory with economic protection (counterpart, alternative or double benefit right);

c) The responsibility assumed by different social actors in the development of inclusion measures and support advocacy for the excluded population.

d) The impact of the monitoring changes and the inclusive measure orientation of the beneficiaries.

\section{The evolution of the inclusion models within the regions}

According to the above evidence, inclusion regulations had a recurring development in the country. However, regional inclusion models have not been static, suffering several arrangements in an effort to tackle the social transformations that occurred in recent decades.

Progressively, advancements were made in understanding social inclusion as a complex phenomenon that requires coordinated and multidimensional responses. Nonetheless, always conditioned by the level and intensity of the difficulties, especially visible during the recent crisis.

\subsection{From activation to multidimensionality recognition}

The analyzed regions show differences in the focus and actions designed. Starting with La Rioja, during the phase prior to the economic crisis (2001-2008) a clear viewpoint of inclusion prevailed based on labour orientation and employment incorporation. During this period, different decrees and laws guided the social action in this regard. The higher or lesser distance from the labour market was used as the main character to divide the vulnerable population and to establish differentiated interventions. Even the minimum income benefit remained segmented in the territory by this variable. The Minimum Insertion Income (IMI) aimed at supporting the socio-labour incorporation of the most employable population groups, while the Social Incorporation Aid (AIS) did the same 
with those less employable whose support was not primarily aimed at labour incorporation.

The high obligations of the recipients in the field of employment (constant maintenance of the employment demand, obligation not to refuse suitable job offers) further underlined the strong activating nature of economic support at this stage. The situation turned even more difficult for those who found fewer opportunities to access employment, either because of their low qualification or work experience or because they still experience some internal issues. In general, the regional minimum income has sought an early exit of the benefit. The permanence in the minimum income programs, except in a few cases (Basque Country and Navarre), has been disconnected from households' difficulties. Likewise, inclusion resources that allowed economic stability without the social benefits have been modest.

This is illustrated, among others, by the case of Murcia Region, where inclusion policies had a very limited lawmaking development compared to the rest of the examined regions. Since 1991, with the Regional Social Insertion Plan (Decree 1/1991), some financial aid (including the Minimum Insertion Income) was incorporated into the social services system. However, it was not until 2002, with the Regional Accompaniment Program for Social Inclusion (PAIN), when the commitment to the promotion of personalized insertion itineraries began. Although this political advance, the translation into practice was very limited and had a slight impact on the intervention model in public social services. Same as in many other territories, this approach gave a partial and deficient response to beneficiaries' demands.

On the other hand, the normative development in the southern region of Andalusia had in its beginnings a clear recognition of the shared social responsibility in addressing exclusion. The Andalusian inclusion model promoted a greater cohesion and territorial integration as a critical element, but not only. At the same time, the regulatory evolution focused on an individual-family insertion model to develop integral interventions where social accompaniment was complemented with a minimum income, training, employment and housing support. The weak coordination between the different actors involved in each of these areas made it difficult to consolidate. In 2003, once the regional government assumed the employment competencies, the socio-labour insertion as the central inclusion component was reinforced. This approach remained practically unchanged until the end of the crisis.

In Castilla y León, a robust regulatory development was identified that progressed from 1988 (after the enactment of the first Social Services Law) until 2012. During this long period, two important milestones could be highlighted; on the one hand, the Regional Sectorial Plan for Social Inclusion (2005), a roadmap based on a multidimensional approach and social co-responsibility. Under this perspective, pioneering initiatives were developed, such as the Comprehensive Support Service for families at risk of eviction, which provided integral support in the financial and social sphere to over-indebted families. 
Similar is the case of Navarre, a region with a notable boost in inclusion policies until 2008. The first Plan to Battle Social Exclusion, a pioneer in the country, was established for the 1998-2005 period, providing the basis for the following decades. Only until recently (2018), a similar roadmap was promoted again. The discontinuity of this type of documentation has also been the pattern in most regions, which made it difficult for the inclusion measures momentum to withstand over time.

One of the most notable elements of the plan mentioned above is that it initiated an interdepartmental and multilateral line of work with essential participation of the Third Sector. Private entities and civil society have played an important role in defining local social agendas. Particularly in Navarre, but also in the rest of the regions, they launched pioneering initiatives identifying and pointing out unmet needs. For instance, under the plan, innovative housing and employment measures were promoted, many of which still survive today (social integration housing programs, socio-labour insertion companies). Although, in practice, the collaboration between departments and social services has been limited to the financial aspect, with the responsibility for their development still falling on the latter. On the other hand, the transformations in the labour and housing market have progressively diminished the inclusive potential of these resources, whose role was gradually devaluated.

From an overall perspective, in most regions, although relevant work started adapting the political responses to the new social realities, this could not be consolidated. These issues have not only made it difficult to respond adequately to the most vulnerable population, especially in those households that accumulate the most significant problems, but they also led to a weak spot when facing the impact of the crisis.

\subsection{Reorientation and territories' withholding to the increase of social needs during the crisis period}

The long-term unemployment progression during the crisis period was a major challenge for regional inclusion policies. Although the increase in unemployment rates had a distinctive evolution in the territories (some regions experienced the impact of the crisis first), the trend in this new scenario has been similar. All the territories examined also responded with regulatory modifications that sought to contain the increased demand for minimum income programs. It is true that in some cases there was a slight increase in the budget, but the fact that this increase was not able to compensate for the volume of demand concluded that the level of support dropped below the pre-crisis response (see Figure III).

Graph III. Evolution of struggling households recipients of the Minimum Income (RMA) benefits and the difference between both indicators. Figures in thousands (2002-2018). 


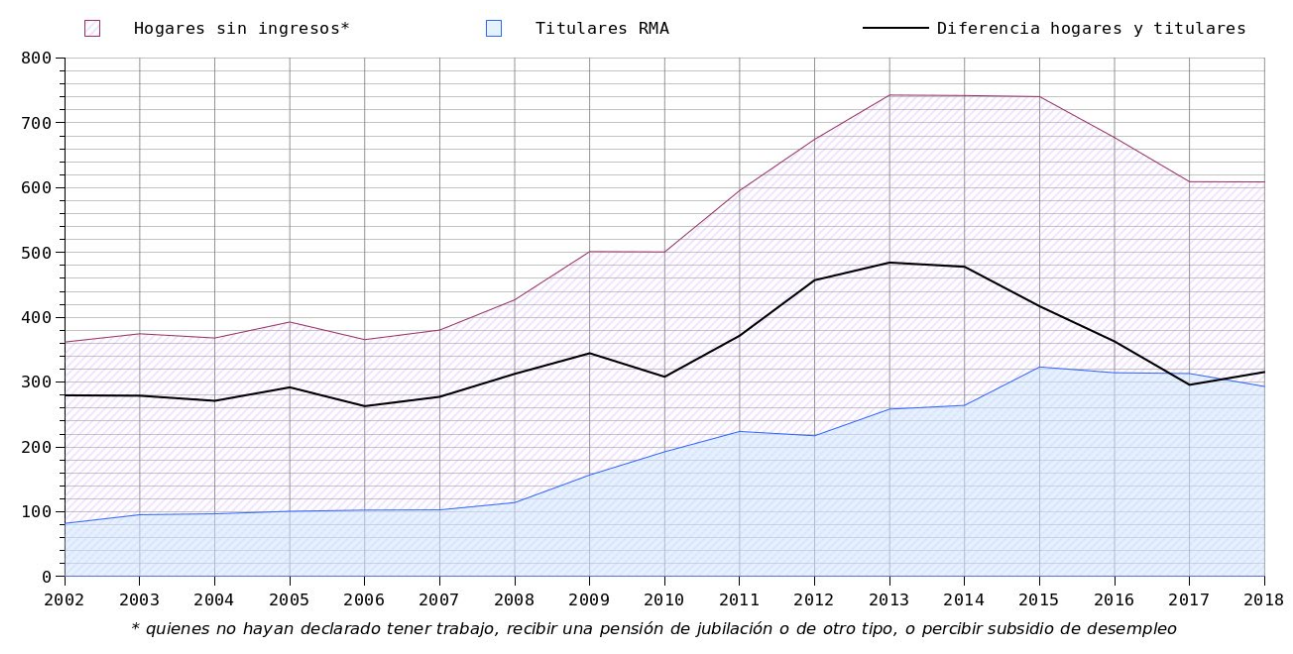

Prepared by the authors based on data from the INE, Annual Reports of Minimum Insertion Income (Ministry of Health, Consumption and Social Welfare).

Nevertheless, the action of inclusive territorial models has not been challenged only by this fact. The technical and professional support provided had to deal, on the one hand, with extreme and diverse cases, on the other, with many households entering social services by combining the financial protection with employment access, both being in many cases the only problems.

The magnitude and diversity of the demands pressured the regional inclusion models' capacity, which finally led to a limited response in some cases to prevent the tightening of exclusion itineraries. All this ended up sharpening the shortcomings that dragged territorial protection systems (inability to give a comprehensive response) and reinforcing the previous negative patterns (simple labour response to the multidimensional phenomenon of exclusion).

Thus, in the first place, the inhibition of inclusion policies in response to the economic crisis was especially intense in the Murcia region. The coverage of the income guarantee aid was significantly reduced as the budget dedicated to these items decreased. In order to replace the lack of public provision in a context of need, third Sector Entities - which played an important role - reinforced their financial dependence with the European Social Fund (ESF in onwards) and the State Plan for Youth Guarantee. These two programs were very oriented towards the improvement of qualification and job training. This fact strongly marked the orientation of these policies, resulting in projects like the Regional Program for the distribution of clothing, footwear and toys developed since 2015.

The impact of the crisis in La Rioja also caused a high increase in the demand for financial aid to meet the basic needs of households. The minimum income benefits tightened the access requirements, limiting the perception period and hardening the obligations of the beneficiaries. Although some of these restrictions happened between 2011 and 2013 (Decree 209/2014), some limitations remained such as the impossibility of combining aid 
support. The most vulnerable households suffered periods of income absence and a severe reduction in their living conditions due to these measures.

The impact of the crisis also called into question the sustainability of the income guarantee system in Navarre, whose provision of minimum income (Basic Income) had been recognized as an individual right (1999). Equally, La Rioja tightened the access and maintenance requirements in the minimum income program in 2012. The new Social Inclusion Income (RIS) that replaced the previous model, prevented accommodation risk to the benefit (reduction in the time spent in the program, periods without any income after benefits exhaustion, hardening the access and maintenance requirements). The reform was harshly criticized by the civil society and the professionals in the social field, due to the lack of protection that this logic caused. As a result of this pressure, the policy underwent up to five different modifications from 2012 to March 2015, which gradually eased their access requirements.

In Castilla y León, with some small modification between 2010 and 2012 (Guaranteed Income of Citizenship), initiated a new stage in 2013, marked by a strengthening of assistance measures and an increase in the relevance of active employment policies. The Family Protection Network (RPF) was promoted also in 2013; however, although trying to continue with the public-private partnerships from the previous decade, in practice, it was limited to extraordinary and palliative measures.

The Andalusian response to the economic crisis was also marked by the development of governmental actions with substantial assistance and activating orientation due to the crisis impact in the region. This is explained, for example, by the decrees of extraordinary and urgent measures for social exclusion (Decree-Law 7/2013) and extraordinary and urgent measures for social inclusion through employment (Decree-Law 8/2014). The Transition to the Employment Program (PROTEJA) provided local administrations with resources to carry out public work that facilitated the temporary incorporation into the labour market and a route of family income to disadvantaged households. Although not all regions today have social employment programs like this, it is still a low-intensity response, since temporary hiring has barely any potential in these cases.

In short, the first response to the crisis implied a significant deterioration in the protection capacity and level of coverage of the 90's minimum income. Similarly, the integral strategy that guided the territories was damaged when trying to respond to the fluctuating social scenario. During this period, there was an essential reinforcement of the inclusion concept as strong support back to the labour market and a palliative response to social problems.

From the state's perspective, this setback contributed to a downward matching process of territorial inclusion models. This dynamic implied a notable reduction in the effectiveness of the inclusion measures, leading, in the first place, to a strong social rejection of the measures and, secondly, opening debates about the need to improve the response capacity of the inclusion models. 


\section{New trends in response to social changes}

However, the review of policy trajectories allows us to identify some milestones that show how progress is being made in the recognition of social inclusion as a complex phenomenon, and how they try to overcome some of these debates exposed throughout the text. Specifically, the analysis of these five territories allowed us to identify different indicators that show some progress in their inclusion policies.

\subsection{Progress in terms of joint responsibility and coordination}

Inclusion as a multidimensional phenomenon demands better coordination between the different areas of the administration to give more integrated and comprehensive responses. Although traditionally, they had been treated as an outlying political action, exclusion dynamics have confirmed the need to focus on more comprehensive approaches. With this objective, the improvement of the coordination between social and employment services has become especially relevant (Scharle et al., 2018). Among others, the extension of social difficulties towards qualified sectors, or the increase in the benefit demand in cases where the main problem is linked to employment, blurred the edges between the beneficiary profiles of each service.

However, the new scenario demands more synchronized attention to avoid duplicities, gaps in the support and to articulate more flexible and adequate labour and training resources. Several initiatives in this regard have recently been launched throughout the regions. Navarre implemented a pilot experience (ERSISI project ${ }^{2}$ ), which promotes the joint work of multidisciplinary professionals (from the social and labour field) who work on each of the cases - exchanging their knowledge and professional background - to adopt a holistic perspective and mobilize the resources and intervention techniques. The results show that the development of diagnoses and the design of joint inclusion itineraries allow adapting interventions to the needs and circumstances of individuals. Ultimately increasing the possibilities of intervention and raising the activation for autonomous management of the household's needs (ALTER, 2019).

As of 2016, the Coordination Protocol to improve the socio-labour insertion began its promotion in Murcia. The protocol was born to simplify referrals between services and favour the design of shared intervention tools. Due to the weak government response, throughout this process, there was also a reassessment of the role that social institutions must-have in the definition of the inclusion models.

The co-responsibility of social actors in terms of inclusion is a trend that is also visible in other regions. Castilla y León adopted this type of actions, such as the Family Protection Network mentioned above (2013). Although it was limited to assisting in emergency responses, the consensus on integral care and networking between public and private actors remains today in the territory. The European project EASI-PACT is a good

\footnotetext{
${ }^{2}$ European innovation project (VS/2016/0209), financed by European Commission and developed between 2016-2019 in Navarre.
} 
example of an innovative experience whose pillar is the impulse of new forms of information management (social history, access to benefits) and consensual work with third sector organizations.

All these experiences, although still in initial stages, advance how better inter-institutional and multi-sector coordination favors not only the effectiveness and efficiency of inclusive policies, but also the construction of more socially responsible territories.

\subsection{Progress in terms of planning and the inclusive agenda promotion}

Undoubtedly, one of the main factors that explain the low consolidation of inclusive projects at the regional level has to do with the underdevelopment of the actions planned. Social service portfolios define both the objectives included in the laws of the social services and indicate the public commitment regarding inclusion. These portfolios not only collect the services to which citizens are entitled to but also seek to order the map of resources available in the territory, adapting the social intervention to the difficulties encountered. However, not all territories have a portfolio of services. Among those analyzed, only Navarre (Foral Decree 69/2008), La Rioja (Decree 31/2011) and Castilla y León (Decree 58/2014) have implemented theirs. In the case of Andalusia, its development was a commitment acquired within the framework of the recently approved Law on Social Services (2017) and is currently under development. In Murcia, on the other hand, there seems to be no similar commitment in the short term, which distances this region from the rest of the territories.

The design of action plans has, for some time now, become an essential instrument of European policy in the fight against poverty and social exclusion. Although the European framework has promoted the development of state plans to transfer the common objectives in social inclusion to this level, the regional and local plans are especially important. They can be crucial in the articulation of inclusion models and, in particular, adapting the intervention to the new social problems, gathering different social actors present in the territory, involving different areas of public administration, and promoting coordinative and innovative actions (housing and social employment programs, public intermediation in cases of eviction).

Experience shows that this alone is not enough. However, it is also necessary that the sectorial plans, such as housing or employment, include measures aimed at serving the most vulnerable sectors of society, a perspective that is beginning to emerge also in territories such as Navarre. In recent years the adaptation has started towards the employment guidance from local employment agencies. It is undoubtedly a mechanism to intensify the commitment for more comprehensive responses, but also to recognize there are needs of certain sectors, that must be met by the competent areas.

\subsection{Advances in terms of right recognition and intervention approach}

Some advance was identified regarding the revision of social inclusion laws and income guarantee and the gradual overcoming of the old fashion assistance logic. Navarre stands 
out as the most advanced territory analyzed. Following some European recommendations and the path marked by other communities such as Basque Country, the double right to economic protection and social inclusion were recognized (Foral Law 15/2016). In other words, there is an explicit recognition that not all users with economic needs require a socio-labour support process, either because they have the necessary autonomy to manage socio-labour incorporation, nor their situation requires a social accompaniment at least in the short term. This logic represents a definitive step in the dissociation between the perception of economic support and inclusive actions.

A steady commitment to the so-called employment stimuli has been proposed to prevent the income guarantee benefits from discouraging access to employment. In the event, that job income does not reach the minimum income benefit, the perception of both sources is approved so that the joint calculation is more significant than just receiving the social benefit. This policy crosses the border of the mere fight against poverty also to favour sectors of the population that receive wages and pensions of modest amounts (Sanzo González, 2013; Zalakain, 2014).

Other regions have also made progress in reviewing their minimum income benefits, and although with minor law implications, they incorporated some remarkable elements. For example, Citizenship Income (2017) establishes flexible access mechanisms for people affected by evictions, refugees, or pregnant women at risk, among other circumstances. A uniquely innovative element is that those who receive and care for others that require continuous attention are exempt from the obligation to accept a job (a widespread requirement by many territories). This implies an explicit recognition of the importance of care, and that, on occasion, socio-labour insertion can be counterproductive in cases such as single-parent families.

The role of social services has been reinforced lately. An example of this is the Social Service Law of Andalusia (2017), which not only takes up the community philosophy but also includes a definition of the inclusion itineraries under a broader logic than mere labour market access. This opens the opportunity to move towards a new conception of inclusive intervention, which requires thinking about other strategies. This is an opportunity to introduce approaches based on community participation and strengthening the promotion of solidarity networks (social activation versus labour). Given the characteristics of our country, future efforts could be directed to the care field (protected family care, reinforcement of informal care and mutual care networks), so that unpaid work can be valued and growing problems can be solved (preventing the consolidation of uprooting or loneliness in the elderly).

\section{Challenges and conclusions}

The comparative study of these 5 Spanish territories allows identifying two phases in their regulatory evolution. The first one, in which there is a progressive overcoming of activation goals and the recognition of the multidimensionality of social exclusion and inclusion. In the second phase, responses were repressed as a result of austerity policies 
during the crisis. This austerity response after the 2008 crisis has also been observed in other European countries (ESN, 2015; Karagkounis, 2016; Pentaraki, 2017).

The analysis indicates that, fortunately, Spain has undergone some changes to reverse this trend. In this regard, from the Spanish experience, five lessons can be identified and exported to other territories and European countries to advance in the development and consolidation of these policies.

Firstly, the Spanish experience clearly evidences that when short-term decisions are made, generally derived from fear of increased demand and spending, the lack of protection and capacity to respond to vulnerable population increases. Thus, to prevent the replication of the same dynamics in the future, it seems necessary to overcome this logic. In fact, given the evidence of the social costs of these decisions, a reformulation heading towards new right recognition has been observed. The intensity is not the same in all the territories, thus cannot be considered as a third consolidated phase. Even so, the idea of a minimum income with low conditionality seems to be consolidated as a more suitable scenario to successful inclusion itineraries.

Secondly, the historical evolution of inclusion regulations in Spain has been marked by the commitment of professional and political actors. The joint responsibility and networking initiatives between the public administration and the emerging social entities - the case of Castilla and León, for example - allows for a clearer map of inclusion resources, helping to develop more comprehensive and prolonged actions in time. Everything points to the fact that those regional inclusion models, combining public leadership with the collaborative participation of public and private actors, are moving towards the consolidation of a greater volume and diversity of inclusion measures.

Thirdly, it should also be noted that improving multi-level and multi-sector coordination is essential to improve the effectiveness of inclusion policies. Although progress has been made integrating social and employment services, this trend needs to be reinforced in areas such as healthcare or education, so that the perspective of inclusion as a complex phenomenon can be translated into a multi-dimensional practice. Along these same lines, seems evident that inclusive actions must incorporate a community tie strengthening, as one more way to meet the growing needs and to prevent situations of social isolation. Therefore, coordination between the administrative systems involved is essential and must be improved to overcome fragmented and less effective responses affecting people of all ages.

It seems necessary to rethink some of the discourses and strategies that have dominated the debate on inclusion policies in the last decades, especially the centrality of employment as the leading inclusive action. The difficulty of fitting this strategy into the life-path of many of the beneficiaries motivates questioning this model. Professionals demand more flexibility — some territories already started addressing it - and less activating pressure. In fact, the experiences analyzed show that when the activating nature of inclusion resources has been reinforced, it has contributed to the lack of protection of 
many households. Therefore, it seems inexcusable to move towards a more inclusive activation strategy based on a support system, guaranteeing stability and well-being, overcoming poverty and leaving the benefits system. Therefore, the fourth lesson takes us to the recognition of the necessary incorporation of multidimensional approaches and actions connected with the community environment.

Finally, the last inclusive result highlights the need to guarantee stable budget allocations and professional teams. Usually, the debate on improving the effectiveness of inclusion policies are oriented towards increasing budget lines and improving the provision of technical and human resources. This is a necessary request to improve the intensity of the response. However, as extracted from the analysis, it is also fundamental to orient the support towards the exact needs and social issues. This has already being debated in some territories, which will surely improve regional responses and consolidate the role of inclusion policies as one of the main tools — although not the only one - to generate more well-being and social cohesion.

Inclusion policies are essential to territorial cohesion. Their local and autonomous character has traditionally contributed to providing them with a residual character within the framework of the most ingrained social policies. Despite this, the advances confirm important steps towards fighting the most structural social inequality, from the local to the regional level. Territories customarily having broad social exclusion spaces could find opportunities to move towards social inclusion. Social and territorial cohesion is key to the national development, inclusive and integrated territorial dynamics have shown significant progress in social inclusion. These actions can also contribute to various European countries, as local policy fragmentation and the emphasis on activation are also features to be found in other nations. Not only is it important as an adaptation element, but also crucial for a harmonized, balanced and cohesive growth.

\section{References}

Abrahamson, P. (1995). Welfare Pluralism: towards a new consensus for a European social policy?. Current politics and economics of Europe, Vol. 5 (1), p. 29-42

ALTER (2019). Claves y resultados del modelo de integración de servicios ERSISI [Keys and results of the ERSISI integrated care model]. Working paper Pending publication

Atkinson, A.; Marlier, E. (2010). Analysing and Measuring Social Inclusion in a Global Context. New York: United Nations

Atkinson, R., \& Davoudi, S. (2000). The concept of social exclusion in the European Union: Context, development and possibilities. Journal of Common Market Studies, 38 (3), 427-448.

Atkinson, T. (2002). The experience of the European Union with the social inclusion policy. In M. Buvinic, J. Mazza, J. Pungiluppi, \& R. Deutsch (Eds.), Social inclusion and economic development in Latin America. Washington: Inter-American Development Bank. 
Ayala, L.; García-Serrano, C.; Arranz, J.M.; Martínez-Virto, L. (2018). El sistema de garantía de ingresos en España: Tendencias, resultados y necesidades de reforma [Income Guarantee system in Spain: trends, results and reform needs]. Madrid: Ministerio de Sanidad, Servicios Sociales e Igualdad.

Cortinas, J. (2017). Génesis de la Renta Mínima de Inserción en Catalunya. Actores, trayectorias, posiciones y recursos [Genesis of the Minimum Insertion Income in Catalonia. Actors, trajectories, positions and resources].Cuad. trab. soc. 30(2), 329-342.

Dalli, M. (2019). Comparing the access conditions for minimum income support in four EU member states for national, EU and non-EU citizens. Journal of Social Welfare and Family Law, 41(2), 233-251.

EUNL (2016). Integrated approaches to combating poverty and social exclusion. Best practices from EU Member States. The Hague: Ministry of Social Affairs and Employment.

European Commission (2015). Social Protection Committee Indicators Sub-group: Portfolio of EU Social Indicators for the Monitoring of Progress Towards the EU Objectives for Social Protection and Social Inclusion. Directorate-General for Employment, Social Affairs and Inclusion. Luxemburg: EU.

European Social Network (2015). Public social services in crisis: challenges and responses. From 2008-2014: a response from ESN members. Report for European Social Network. Brighton: ESN.

European Social Network (2016). Connecting local with local communities. Brighton: ESN.

Daly, M., \& Silver, H. (2008). Social exclusion and social capital: A comparison and critique. Theory and Society, 37 (6), 537-566.

Ferrera, M. (2005). The Boundaries of Welfare: European Integration and the New Spatial Politics of Social Protection. London: Oxford University Press.

FOESSA (2014). VII Informe sobre exclusión y desarrollo social en España 2014[VII Report on exclusion and social development in Spain 2014]. Madrid: Fundación FOESSA.

FOESSA (2018). VIII informe sobre exclusión y desarrollo social en España 2018 [VII Report on exclusion and social development in Spain 2018]. Madrid: Fundación FOESSA.

Förster, M. ;Maas ,F.; Marin, B. )2003(. Understanding social inclusion in a larger Europe: an open debate: proceedings from the general asembly meeting of the European Centre. European Centre for Social Welfare Pol-icy and Research. Indiana: Indiana University. 
Frazer, H., \& Marlier, E. (2014). Assessment of progress towards the Europe 2020 social inclusion objectives: Main findings and suggestions on the way forward. Brussels: European Commission.

Gallego, R., Subirats, J., \& Gomà, R. (2003). Políticas sociales y gobierno multinivel el España [Social policies and multilevel government in Spain]. In R. Gallego, J. Subirats, \& R. Gomà, Estado de bienestar y comunidades autónomasla descentralización de las políticas sociales en España [Welfare State and Autonomous Communities: The Decentralization of Social Policies in Spain] (pp. 213-229). Barcelona: Technos.

Jaraíz Arroyo, G. \& González Portillo, A. (2019). The impact of local inclusion policies on disadvantaged urban areas: perceptions in the case of Andalusia. Investigaciones Regionales - Journal of Regional Research, 44, 47-62.

Johnson, N. (1990). El estado de bienestar en transición la teoría y la práctica del plura-lismo de bienestar [The Welfare State in Transition The Theory and Practice of Pluralism of Welfare]. Madrid: Ministerio de Trabajo y Seguridad Social.

Karagkounis, V. (2016) Social work in Greece in the time of austerity: challenges and prospects, European Journal of Social Work, 20:5, 651-665

Laparra Navarro, M., \& Pérez Eransus, B. (2012). Crisis and social fracture in Europe. Barcelona: La Caixa.

López-Santana, M., \& Moyer, R. (2012). Decentralising the active welfare state: The relevance of intergovernmental structures in Italy and Spain. Journal of Social Policy, 41(4), 769-788.

Manzanera-Román, S., Carbonero, D., Hernández, M., \& Raya, E. (2019). Modelos de inclusión uniprovinciales en España: similitudes y diferencias en La Rioja y Región de Murcia [Uniprovincial inclusion models in Spain: similarities and differences in La Rioja and Murcia Region]. Investigaciones Regionales - Journal of Regional Research, 2019/2 (44), 29-45.

Martínez Virto, L. (2014). Surviving the crisis: Strategies of households in difficulty. Barcelona: Bellaterra

Martínez Virto, L.\& Sánchez Salmerón, V. (2019). Regional inclusion policies in Spain: new approaches and keys to their effectiveness. Investigaciones Regionales - Journal of Regional Research, 2019/2 (44), 17-28.

Moreno Fernández, L. (2001). Pobreza y exclusión: La malla de seguridad en España [Poverty and exclusion: The safety nets in Spain]. Madrid:CSIC.

AEDGSSSS. (2019). XIX Dictamen del observatorio 2019 [XIX Opinion of the observatory 2019]. Málaga: Asociación estatal de directores y gerentes en servicios sociales. 
OCDE (2017). Understanding the socio-economic divide in Europe. [on line] https://www.oecd.org/els/soc/cope-divide-europe-2017-background-report.pdf

Pentaraki, M. (2017) Practising social work in a context of austerity: experiences of public sector social workers in Greece, European Journal of Social Work, 22:3, 376387, DOI: $10.1080 / 13691457.2017 .1369396$

Pérez Eransus, B. (2016). Una propuesta para analizar las politicas de inclusión [A proposal to analyze the inclusion policies]. Revista Española del Tercer Sector, 33, 4763.

Pérez Eransus, B. ; Zugasti Mutilva, N. \& Martínez Sordoni, L. (2019). Coordinación interdepartamental y modelos de integración de servicios para la inclusión [Interdepartmental coordination and service integration models for inclusion]. Investigaciones Regionales - Journal of Regional Research, 44, 81-95.

Prieto Lobato, J. ; Rodríguez Sumaza, C. \& de la Rosa Gimeno, P. (2019). Las relaciones entre administraciones públicas y Tercer Sector en el marco de las políticas de inclusión social en Castilla y León [Relations between public administrations and the Third Sector in the framework of social inclusion policies in Castilla León]. Investigaciones Regionales - Journal of Regional Research, 44, 63-79.

Reuter, C. (2012). Facing New Challenges: Promoting active inclusion through social innovation. Solidar, European network of NGOs n ${ }^{\circ} 56$. Brussels: EU.

Rodriguez-Cabrero, G. (2004). El Estado de Bienestar en España: Debates, desarrollo y retos [The welfare state in Spain: Debates, development and challenges]. Madrid:

Editorial Fundamentos.

Rodríguez Cabrero, G., \& Marbán Gallego, V. (2011). Estudio comparativo sobre estrategias de inclusión activa en los países de la Unión Europea [Comparative study on active inclusion strategies in the countries of the European Union] (Reports, Study and Research). Madrid: Ministry of Health, Social Policy and Equality.

Sanzo González, L. (2013). La Política de Garantía de Ingresos en Euskadi [The income guarantee policy in Euskadi]. Zerbitzuan, 53, 9-28.

Scharle, Á., Duell, N., Minas, R., Fertig, M., \& Csillag, M. (2018). Study on integrated delivery of social services aiming at the activation of minimum income recipients in the labor market - Success factos and reform pathways. Budapest: European Commission http://www.budapestinstitute.eu/KE-04-18-545-EN-N.pdf

SIIS, Martínez Virto, L.; Manzano M.A.; Santos, C.; De la Sierra, C.; Hernandez Echegaray, A.; Aguilar Idañez, M.J. (2017). Los Servicios Sociales en otras Comuni-dades Autónomas del Estado Español. Estudio de casos [Social Services in Spanish Autonomous Communities. Five case studies]. Zerbitzuan. No63. Pp: 5-48. ISSN: $1134-$ 7147 
Sachs, J., Schmidt-Traub, G., Kroll, C., Lafortune, G., Fuller, G. (2019): Sustainable Development Report 2019. New York: Bertelsmann Stiftung and Sustainable Development Solutions Network (SDSN).

Silver, H. (2012). Framing social inclusion policies (World Bank Social Development Department's Flagship Study on Social Inclusion Working Paper). New York: World Bank.

Silver, H. (2015). The contexts of social inclusion (United Nations Department of Economic and Social Affairs Working Papers No. 144). New York: United Nations.

Taylor-Gooby, P., Leruth, B., \& Chung, H. (2017). After Austerity: Welfare State Transformation in Europe after the Great Recession. Oxford: Oxford University Press.

Van Lancker, A. (2016). Report on current experiences and trends in the reform of mínimum income schemes in the countries of the European Union. Madrid: MSCBS

Vilá, A. (2010). Cambios legislativos en servicios sociales [Legislative changes in social services (2000-2009)]. In D. Casado, Leyes de servicios sociales en el siglo XXI [Social services laws of the 21st century] (pp. 17-48). Madrid: Caritas

Zalakain, J. (2014). El papel de los sistemas de garantía de ingresos en el abordaje de la pobreza en el empleo: la experiencia del País Vasco [The role of income guarantee systems in addressing poverty in employment: The experience of the Basque Country]. Lan Harremanak, 31, 36-62. 